IOS Press

Editorial

\title{
Health fraud
}

This issue of Pharmaceuticals Policy and Law addresses the theme of health fraud, misinformation, quackery and social determinants.

Professionals in the health sciences sector, academia, law and business as well as government agencies share a responsibility to help consumers to protect themselves from deception and exploitation in health-related matters. The scientific process is essential for discovering truths and validating health claims and information.

Quackery can be broadly defined as "anything involving unsubstantiated promotion in the field of health." Quackery was once a commonly used term within the pharmacy and medical communities. However, an increasingly anti-scientific climate culminated in recent year which granted unprecedented legitimacy to all types of "health claims" that had not been scientifically proven to be effective and/or safe.

In part, this was facilitated when professional magazines, journals and web pages published advertisements and articles promoting these unproven medications.

Society and Governments need to know the full extent of these practices and what organisations of health professionals and their members, consumer organisations, policy makers, and politicians can do to reduce health fraud.

Professor W. Steven Pray says in his essay that the United States has undergone a resurgence of quackery since 1994 that far eclipses the situation in the $1800 \mathrm{~s}$, both in impact on the public and in the unprecedented and daunting political power enjoyed by the forces of quackery. This situation must not be repeated in the European Union. In order to help protect the EU from a similar fiasco, his paper explores various aspects of the US calamity. The author also hopes that the EU can halt the actions of professional organizations that ignore the evidence-based approach to medicine in their rush to participate in the financial rewards arising from their endorsement of quackery.

Pharmaceuticals, Policy and Law has the same objectives.

José Luis Valverde

Editor 